\title{
Using Information Technology to Improve the Quality of Education in Areas Lacking Educational Resources: Taking Southwestern Guizhou Prefecture in Guizhou, China as a Sample
}

\author{
Jiliang Huang \\ Southwestern Guizhou Buyi and Miao Autonomous Prefecture, Xingyi \\ 562499, Guizhou, China
}

\begin{abstract}
Comprehensively improving the quality of education in resource-poor areas is an urgent challenge to achieve balanced development of basic education in China. In the process of educational development in resource-lacking areas, information technology has: (1) changed the traditional teaching mode and teaching environment, (2) provided high-quality educational resources, (3) promoted the professional development of teachers, and (4) promoted the overall improvement of education quality. Southwestern Guizhou Prefecture in Guizhou Province, China, has become a typical case in using information technology to promote education quality improvement in areas with scarce educational resources. This article explores educational information technology in the region as an example to discuss how to grasp the regional characteristics and local needs in the layout of information technology, integrate information technology into teaching practice, and steadily improve the overall teaching quality of the region.
\end{abstract}

Science Insights Education Frontiers 2021; 9(1):1199-1212.

Doi: 10.15354/sief.21.re039

How to Cite: Huang, J. (2021). Using information technology to improve the quality of education in areas lacking educational resources: Taking Southwestern Guizhou prefecture in Guizhou, China as a sample. Science Insights Education Frontiers, 9(1):1199-1212.

Keywords: Information Technology, Resource-Poor Areas, Southwestern Guizhou Prefecture, Education Quality 
Huang. Information Technology to Improve the Quality of Education in Guizhou, China.

Correspondence to: Jiliang Huang, Head of Audio-visual Education and Educational Equipment Section, Education Bureau, Southwestern Guizhou Buyi and Miao Autonomous Prefecture, Xingyi City 562499, Guizhou Province, China. E-mail:284868738@qq.com

Conflict of Interests: None.

(C) 2021 Insights Publisher. All rights reserved.

(c) (i) (2) Creative Commons Non Commercial CC BY-NC: This article is distributed under the terms of the Creative Commons Attribution-NonCommercial 4.0 License (http://www.creativecommons.org/licenses/by$\mathrm{nc} / 4.0 /$ ) which permits non-commercial use, reproduction and distribution of the work without further permission provided the original work is attributed by the Insights Publisher. 


\section{Question}

$\mathrm{D}$ UE to historical, geographic, and natural reasons, the ethnic minority areas in the border areas of China have a low starting point, small scale, and low quality of teaching. Compared with the national education level, there is a significant gap. Technology is regarded as an essential means to influence education development, especially the influence of information technology on education development. $\mathrm{Xu}$ and Luo (2009) believe that the application of information technology to design and develop ethnic-cultural courses and participate in network communication has an invaluable effect on improving the quality of education in resource-poor areas.

In recent years, the implementation of policies such as the "Rural Distant Project" "Reconstruction Plan for Weak Schools in Rural Compulsory Education"르, and "Full Coverage of Digital Education Resources in Teaching Sites" has been adopted. And China has invested a lot in "weak" schools in compulsory education in poverty-stricken areas, including marginal ethnic regions, western regions, and rural areas. It has extensively promoted educational modernization in schools at the stage of basic education in remote ethnic areas. Many educational information technology hardware and resources have been rapidly deployed in elementary and middle schools in ethnic areas, enabling local students to share high-quality educational and teaching resources and receive a good education in an information technology environment (Yang \& Liang, 2006).

Southwestern Guizhou Buyi and Miao Autonomous Prefecture in Guizhou Province was established in 1982. It is one of the youngest among the 30 ethnic minority autonomous prefectures in China. It is located in the hinterland of southwestern China, covering an area of 16,800 square kilometers. It is home to 35 ethnic groups, including Han, Buyi, and Miao, among which ethnic minorities account for $42.47 \%$ (Guizhou Provincial Development Research Center, 2013). As a minority-dominated region, in the context of a relatively harsh natural environment and a relatively poor economic foundation, the regional education foundation is weak. Based on the "Southwestern Guizhou Prefecture Education History," from 1949 to 1950, only 82 high school students were enrolled; and from 1978 to 1979, there were 12,783 high school students. In 1978, colleges and universities enrolled 554 persons, including 323 undergraduates and 322 associates (Sun, 2019). So, catching up with the national-level education became a challenge, and information technology construction has become an important starting point.

Before 1997, Southwestern Guizhou Prefecture had set up video playback points in elementary and middle schools in the county town and very few township sites. At that time, four middle schools at the county level and above had phonetic classrooms, and four county-level middle schools set up computer classrooms with their funds. More than 2,000 schools across the prefecture only rely on chalk, blackboard, and dictation (He \& Liu, 2016). After 1997, China's “Full Coverage of Digital Education Resources in Teaching Sites" project and the Guizhou Province "Modern Educational Technology Experimental School" project have been implemented. Therefore, the re- 
mote mountainous areas of the prefecture have been significantly improved in terms of insufficient teachers, single courses, and low teaching standards.

By the end of 2004, 337 computer engineering project schools in the prefecture, with 10,919 computers, 1,308 televisions, 123 multimedia projection classrooms, and 82 schools, established campus LANs. In 2005, the province fully launched the modern rural distance education project construction project, equipped with 1,617 "Rural elementary and middle school distance education project engineering schools" in Southwestern Guizhou Prefecture (Southwestern Guizhou Education Public Service Platform, 2015).

Since 2013, Southwestern Guizhou Prefecture has closely followed the pace of China's information technology development and issued the "Southwestern Guizhou Prefecture Educational Information Technology Project Implementation Plan.” It clarified work goals and tasks and completed the construction of the hardware environment of the "three links and two platforms" through the model of "government-enterprise cooperation, school-enterprise cooperation, and school-school cooperation" (Chen et al., 2019).

While information technology equipment is deployed, how to deeply integrate information technology with education and teaching to promote the improvement of teaching quality and the development of students is now an urgent problem for education in ethnic minority areas. Some scholars have investigated the current situation and application of educational technology equipment in schools in ethnic regions and pointed out that teachers lack initiative in learning and using modern educational technology, and the related teaching facilities purchased are rarely used for teaching practice and are artificially idle. Lack of funds restricts the purchase and renewal of modern teaching equipment and cannot keep pace with the development of modern educational technology. At the same time, various software resources supporting modern education and teaching are insufficient and lacking features (He, 2006; Li et al., 2017).

In response to these problems, Southwestern Guizhou Prefecture, relying on the Chinese platform and supported by big data technology, boldly explores a new " $1+4+\mathrm{N}$ " education cloud big data development model. This depends on a platform (Jin Zhou Education Cloud Platform) to highlight the four major functions (targeted poverty alleviation, education fairness, balanced development, and quality improvement), forming a circle centered on Jin Zhou Education Cloud big data. This will drive the radiation of $\mathrm{N}$ regional schools and related work in the surrounding areas to "Internet + collaborative lesson preparation before class, + platform online live broadcast, + integration of learning, teaching, research, and training, + online and offline training, + teaching skills improvement, + education group assistance" (Wei, 2017).

In just a few years, Southwestern Guizhou Prefecture has gone from consolidating infrastructure construction to exploring multi-school cooperation with the help of the Internet, hand-in-hand cooperation, strong schools leading weak schools, to achieve education balance and quality improvement in ethnic areas. At the same time, with the "Relying on "Jin Zhou Education Cloud Platform" to expand the Coverage of Highquality Educational Resources," the typical case won the "Fifth China Education Re- 
form and Innovation Excellence Award." The Panjang Road Elementary School in Xingyi City of the prefecture was selected as an excellent national school for online learning space application and a particular training base school for online learning space. Southwestern Guizhou Prefecture has achieved tangible results in the ongoing promotion of educational information technology and formed a sample of information technology leading the development of education (Jin, 2019).

\section{Relying on China's National Platform to Build Jin Zhou Education Cloud Platform}

In March 2016, China's public service platform for basic education resources was launched in Southwestern Guizhou. It opens the use and exploration of Southwestern Guizhou Jin Zhou's educational cloud platform, "cloud + terminal." To promote the sharing of excellent educational resources in remote and impoverished minority areas and to improve the quality of shared education, Southwestern Guizhou Prefecture took the opportunity of the establishment of China's educational resources public service platform in Southwestern Guizhou, according to its educational information technology level and the characteristic needs of educational resource networking. They quickly started the "six constructions," including high-speed construction, platform construction, terminal construction, space construction, team construction, demonstration construction. With the construction of four databases for teachers, students, parents, and courses as the core, and wisdom management and teaching as the starting point, we will build a cloud platform that brings together high-quality education and teaching "massive knowledge resources" from China, provinces, enterprises and local governments, and realizes the cloudification of resource collection, The integration of learning, teaching, research and training, and the wisdom of the management process.

\section{Construct a "High-Speed" Network}

By the principle of "unified plan, unified standards, unified construction, unified supervision, nearby access, and hierarchical management," a high-speed private network covering "Gigabit to school and 100M to desktop" covering elementary and middle schools in all prefectures will be built to achieve Optical fiber network "School-School Link."

\section{Construct a School Platform}

Taking the construction of information technology infrastructure as the forerunner, relying on the education cloud platform and big data center, with the four databases of teachers, students, parents, and courses as the core, and wisdom management and teaching as the starting point, 108 online live classrooms or interactive teaching demonstration schools have been built, and 329 schools have opened wisdom campus services. 


\section{Construct a Terminal}

There are 1,668 elementary and middle schools (kindergartens) in the whole prefecture, with a total of 10,663 teaching classes and function rooms to achieve "high-quality resource class-to-class access."

\section{Construct Space}

Integrating various applications such as teaching, management, learning, and communication, the sharing of high-quality educational resources will lay the foundation for innovative learning forms. Through the "learning space for everyone," teachers, students, and parents conduct independent online learning and interactive teaching exchanges. As of March 2020, among the 1,718 schools in the state, 2.5 million "online learning spaces for everyone" have been registered with real names, 57,000 teachers, 979,768 students, and 1,460,200 parents. The total capacity of the downloadable resources on the platform is $27.8 \mathrm{~T}$, of which $15 \mathrm{~T}$ is the landing resource in China, 83 applications of various types, and 37 core applications. More than 5.639 million pieces of material resources (including courseware, teaching plans, pictures, video, and audio), 1.333 million teaching classrooms, 32,000 micro-classes, nearly 16 general high school elective online courses, more than 156,000 unique educational resources and topic resources. Schools in all prefectures and states have achieved "Broadband Network School-toSchool Connection," with a network coverage rate of $100 \%$. By constructing a learning model that "can learn by everyone, can learn everywhere, and can learn all the time," individual learning activities can be realized (Zha, 2019a).

\section{Construct a Team}

With a large-scale application resource platform as the core and training as a breakthrough point, it adopts the training methods of "send out, invite in" and "localization" to strengthen the construction of four teams of administrative leaders, core talents, key teachers, and ordinary teachers. Finally, the awareness of education information technology has been strengthened, and the driving force for the application of the education cloud platform has been formed.

\section{Construct a Demonstration}

Establish 20 schools represented by Xingyi No. 1 Middle School in Guizhou Province as Southwestern Guizhou Prefecture's 2020 educational information technology application pilot schools. The Prefectural Education Bureau provides policy support to the pilot schools regarding construction, application, training, and promotion. It selects 1-3 provincial teachers from Southwestern Guizhou Prefecture from the pilot schools to become members of the development center's educational information technology application and promotion expert database. Take the pilot school as the vanguard, actively 
explore, sum up the experience in practice, form a model, and then gradually promote it to create a demonstration, leading, and radiating role.

The construction and application of Jin Zhou Education Cloud are based on the "cloud +" model to promote the in-depth integration of information technology and education and teaching. It uses educational information technology to drive the modernization of education, vigorously promote the modernization of education, teaching, and management methods, improve the quality of education, and solve complex problems such as education fairness and education balance.

In January 2018, Jin Zhou Education Cloud Platform won the "Fifth National Education Reform and Innovation Excellence Award." In the same year, Panjang Road Elementary School in Xingyi City was selected as the National Excellent School of Online Learning Space Application. In 2019, it was chosen as a candidate school for the 2019 Online Learning Space Special Training Base School of the Ministry of Education (Liu, 2019).

\section{Take Advantage of Jin Zhou Education Cloud Plat- form to Promote the Development of "Internet +" Teachers.}

The professional development of teachers is one of the critical factors to improve the quality of school education (Darling-Hammond, 2000). Hanushek (2011) found through research that if $5 \%$ to $8 \%$ of the worst quality teachers in the United States are replaced with average teachers, the United States can be close to first place in the international mathematics and science rankings. This is equivalent to creating an economic value of 10 trillion US dollars. Therefore, strengthening the professional development of teachers is also of great significance for promoting the quality of basic education in China.

To break through the geographical limitation of teachers, Southwestern Guizhou Prefecture actively promotes the professional development of teachers through a combination of online and offline methods. On the one hand, by carrying out activities such as sending teachers to famous teachers and famous schools, expert lectures, special meetings, teacher skill competitions, key teachers, and selection of renowned teachers, the scope of training is expanded and the training efficiency is improved. Use "schoolschool pairing" and "famous teacher pairing" activities to realize the sharing of highquality teachers and promote the balanced development of education. On the other hand, in the "Internet +" environment, through Jin Zhou education cloud platform + shared classroom (prestigious schools, famous teachers, high-quality and urban and rural simultaneous classroom delivery), "Jin Zhou education cloud platform + school management," Jin Zhou education cloud platform +Teachers prepare for lectures "Jin Zhou Education Cloud Platform + Online One-course Two-Teacher Teaching," Jin Zhou Education Cloud Platform + Online Same Class Heterogeneous," etc., to make up for the shortage of teachers in remote areas and the lack of high-quality curriculum resources. At the same time, it achieves the effect of accurately assisting a group of rural schools, 
improving teacher education and teaching ability, and realizing the " $1+\mathrm{N}$ " education model that integrates learning, teaching, research, and training.

\section{Collaborative Preparation before Class}

According to the teaching goals, the lecturer completes the teaching design of the new knowledge points of the course and collects related resources, uploads them to the personal space, and publishes them to $\mathrm{N}$ remote teachers in the lecturer space. The remote teachers and the principal lecturer express their opinions, conduct online exchanges, and discussions, and optimize and perfect the lecture preparation of the principal lecturer. The main lecturer and remote teachers carry out tutoring and classroom practice trials according to their students' conditions to prepare both teaching materials and students during the whole process.

\section{The Platform is Live Broadcast Online}

The principal lecturer teaches in the main classroom and uses the live broadcast platform to spread through the "optical network" to remote elementary and middle schools and teaching points in rural areas lacking teachers and teaching. In teaching new knowledge, the main teacher completes the teaching, and the remote teacher guides the students in the class to learn together. After the new knowledge learning is achieved, the main lecturer and the remote teacher will each teach the students in the class to complete the consolidation of knowledge and classroom exercises and complete the teaching objectives and tasks of the course.

\section{Integration of Learning, Teaching, Research, and Training}

Through the teaching of the main teacher, students learn new knowledge and complete the learning process. In the teaching process, the remote students and the anchor students learn excellent learning habits and finally form a good learning atmosphere to complete the education process. The lecturer and remote teachers prepare lessons collaboratively, improve each other, and complete the teaching and research process. The main lecturer uses his unique teaching methods to teach, and remote teachers learn their teaching methods to improve their professional level and complete the training process.

\section{Combination of Online and Offline Training}

Actively carry out inter-regional teachers' online collaborative research and training to promote teachers' peer exchanges. Through famous teachers (famous principals) studios, renowned teachers, and backbone teams as leaders, network learning spaces are used as research carriers, and collective lesson preparation, observation, research, and other methods to promote the organic integration of teaching, researching, and training, and 
to give full play to the basic role of school-based study and training and promote the comprehensive reform of the training model.

\section{Deepened Application Led by Famous Teachers}

To deepen the "Jin Zhou Education Cloud," promote the in-depth integration of information technology and education and teaching, cultivate the backbone of education information technology application disciplines, provide a reference for the construction of "smart education" in schools across the prefecture, and make good use of the application of the "Jin Zhou Education Cloud" platform Guidance, service and professional development of teachers. In March 2020, seven "Jin Zhou Education Cloud" information technology master studios were established, and well-known domestic professors were hired as consultants and experts. The trainees came from the leaders of various disciplines and state-level backbone teachers across the prefecture. Organize and carry out teacher information technology application skills training, study the in-depth integration of educational information technology and disciplines, improve the quality of education and teaching with big data, and develop education and teaching resources for corresponding fields.

Jin Zhou's education cloud platform has solved educational imbalance, narrowed the gap between urban and rural areas, and promoted educational equity. It has realized the construction of a new carrier of "learning, teaching, research, and training," comprehensively enabled the "cloud + terminal" application of educational information technology, actively explored a new model of teacher development in ethnic areas under the background of "Internet + ," and comprehensively promoted the "Internet + " teacher training.

\section{Multi-Dimensional Model Based on the Internet to Promote Regional Education Quality Improvement}

In minority areas, rural education is a shortcoming, and teaching sites are the location of the problem. Faced with this reality, Southwestern Guizhou Prefecture has created various models to solve the problem of insufficient rural teachers and shortage of highquality curriculum resources through the "cloud + terminal" Jin Zhou education cloud under the "Internet +" environment. This has achieved the effect of accurately helping a group of rural schools and improving regional education and teaching (Hai, 2021).

\section{Use the Famous Teacher Studio to Lead the Improve- ment of Teaching Quality}

Nine famous teachers were selected from prestigious schools such as Xingyi No. 8 Middle School, Xingyi No. 1 Middle School, Xingyi Middle School, other prestigious schools in the prefecture, and nine high-quality talent training studios were established. Through online training and offline seminars, various work such as studio construction 
and learning, key teacher training and training, college entrance exam preparation guidance, poverty alleviation, and education are carried out. Through the review and training seminars and seminars before the college entrance examination, the college entrance examination papers were split to create a question bank, dozens of high-quality documents and courseware were shared, and the common learning consensus was shared, benefiting thousands of teachers and tens of thousands of students in the third year of high school.

\section{Carry Out a Variety of Teacher Skill Competitions to Promote the Professional Growth of Teachers}

Southwestern Guizhou Prefecture regularly organizes diversified teacher skill competitions every year. Through the selection and recommendation of outstanding players to participate in the prefecture-level finals, they fully demonstrated their high professionalism and on-site adaptability and demonstrated a high level of teacher skills, allowing teachers to compete and communicate while promoting the improvement of education and teaching skills. For example, the micro-class competition held every year aims to promote the deep integration of information technology and subject teaching, to improve teachers' professional quality and teaching level, improve classroom efficiency and teaching quality, promote the sharing of high-quality resources, and cultivate and create high-quality local digital resources. In 2019, there were a total of 5,176 microclass competitions. After state-level review, $20 \%$ of the works $(1,035)$ were selected and submitted to the Provincial Department of Education to participate in the provincial-level competition.

\section{Firmly Pair the Concept of Assistance and Transfer, and Share the Fruits of Education}

Make full use of the role of demonstration, guidance, and radiation of excellent schools in the prefecture to promote the overall quality of the teaching staff of schools across the prefecture. Make full use of the Jin Zhou education cloud platform to integrate highquality educational resources in the state. Through the combination of online and offline methods, school-to-school exchanges and assistance cooperation are effectively carried out. The two sides learn from each other's strengths, share the new achievements and typical experience of reform and development in education and teaching management, curriculum reform, education quality improvement, and the promotion and application of educational information technology, and seek a new path for education development.

\section{Bring in Strength to Help Guizhou Move Forward}

(i) Through online synchronization of classrooms and direct recording and broadcasting, the model of Wuhan No. 11 Middle School was introduced. The remote live broadcast of college entrance examination guidance in Southwestern Guizhou Pre- 
fecture has promoted the transformation of the state's teachers' third-year teacher education and teaching mode and the steady improvement of the quality of the college entrance examination (Zou, 2018).

(ii) Through the school-local cooperation model with Guangdong University of Foreign Studies, a new model of "National Famous Teacher + Jin Zhou Famous Teacher Studio + Jin Zhou Famous Teacher + Jin Zhou Teacher" was established on the Jin Zhou Education Cloud Platform to comprehensively and effectively improve the classroom teaching of English teachers. And the quality of education and teaching (Cen, 2018).

(iii) The Ningbo wisdom education platform and Jin Zhou education cloud are connected and used through the support and training in Ningbo, Zhejiang Province. It enables teachers in Southwestern Guizhou Prefecture to use Ningbo's high-quality resources to assist classroom teaching and transforms the teacher's education and teaching mode (Zha, 2019b).

(iv) After several years of development, the quality of education in Southwestern Guizhou Prefecture has been steadily improved. In 2019, Southwestern Guizhou Prefecture's undergraduate admission rate and admission rate both increased. A total of 26,930 candidates participated in the college entrance examination. Thirteen thousand eight hundred one reached the undergraduate admission line, with an increase of 1,219 over 2018, and the undergraduate reach rate was $51.27 \%$. Undergraduate admissions were 13,771 candidates (including 3,350 admissions for the first category and 10,421 admissions for the second category). The undergraduate admission rate was $51.15 \%$, an increase of 0.68 percentage points from 2018 of $50.47 \%$, and the number of admissions increased compared with last year was 1077 . On the other hand, the number of high-quality candidates has increased significantly. In 2019, a total of 29 students enrolled into Tsinghua University and Peking University (16 into Peking University and 13 into Tsinghua University), accounting for nearly one-third of the total number of students admitted to Tsinghua University and Peking University in Guizhou province (Southwestern Guizhou Prefecture Education Bureau, 2019).

\section{Concluding Remarks}

With the gradual improvement of China's educational infrastructure, the development of information technology, and the application of the Internet, the nationwide educational information technology infrastructure is becoming more and more complete. According to data from the China Education Information Technology Work Management Information System, as of the end of 2020, the national elementary and middle school network access rate has reached $100 \%$, and non-networked schools have been dynamically cleared. The proportion of schools with an export bandwidth of more than 100M reaches $99.92 \%$. Approximately $98.35 \%$ of elementary and middle schools have multimedia classrooms, with the number reaching 4.29 million, of which $83.16 \%$ of the 
schools achieve full coverage of multimedia teaching equipment (Science and Technology Department of the Ministry of Education of China, 2021).

In the era when the "Internet +" wave is sweeping, Southwestern Guizhou makes full use of the Jin Zhou education cloud platform with the help of Internet technology to give full play to the advantages of "cloud" + "end" and break through the limitations of time and space. With the help of terminal equipment and mobile devices, a service system for delivering education to prefectures, prefectures to counties, counties to townships, and townships to villages within and outside the province has been preliminarily constructed. Let remote minority mountainous schools share the resources of famous schools and teachers and share advanced educational concepts and teaching methods. This fundamentally solves the shortcomings of the inability to enter and retain teachers in rural schools and the severe shortage of subject teachers, narrows the gap in educational development between urban and rural areas and schools, and solves educational imbalance. At the same time, it has also allowed outstanding schools and teachers to achieve a higher level of improvement and has allowed remote rural schools and teachers to achieve rapid development. This has promoted the overall improvement of the quality and level of education, provided successful experiences for the development of education in remote and impoverished ethnic minority areas, and explored a new development path for targeted poverty alleviation with educational information technology (Wang, 2021).

\section{Notes}

1. "Rural Distant Project" is called the modern distance education project for rural primary and secondary schools. It means to promote the sharing of high-quality educational resources in urban and rural areas and improve the quality and efficiency of rural education. Since 2003, it has adopted information technology to adopt three modes: teaching CD broadcasting points, satellite teaching viewing points, and computer classrooms to transfer high-quality educational resources to the rural teaching method pilot project.

2. The Reconstruction Plan for Weak Schools in Rural Compulsory Education was proposed by the Ministry of Education and the Ministry of Finance of China in 2010. Its overall goal is: per the strategic requirements for promoting the standardization of compulsory education schools, to equip rural mandatory education schools with books, experimental educational equipment, and sound, sports, and beauty equipment following the basic national standards. By the requirements of the nutrition improvement plan for rural compulsory education students, gradually improve the eating conditions of rural schools. Under educational planning and existing financial resources, the boarding facilities of rural schools in considerable labor exporting provinces and areas with particular difficulties should be rebuilt and expanded, and boarding conditions should be improved, so that county and town schools can gradually meet the class size standards set by the state. 
Huang. Information Technology to Improve the Quality of Education in Guizhou, China.

\section{References}

Cen, N. (2018, May 05). Three years of benevolence and love to teach road education and poverty alleviation true feelings-Guangdong University of Foreign Studies went to our prefecture to carry out precision assistance training in English education. Qianxinan Daily, p.A3. Retrieved March 10, 2021 from http://www.qxnrb.com/html/201805/05/content_264816.htm

Chen, Y., Huang, D., \& Bai, S. (2019, December 10). Education informatization opens up nerve endings and helps alleviate povertySidelights on education informatization in Qianxinan Prefecture to promote education poverty alleviation in ethnic areas. Qianxinan Daily. Retrieved April 10, 2021, from https://www.gzstv.com /a/70a52e8c0c504d0ebbfaf8a9f00af7cb

Darling-Hammond L. (2000) Teacher quality and student achievement. Education Policy Analysis Archives, 2000(8):1. DOI: https://doi.org/10.14507/epaa.v8n1.2000

Development Research Center of the People's Government of Guizhou Province. (2013, February 18) Basic Overview of Qianxinan Prefecture. Retrieved March 28, 2021, from http://drc.guizhou.gov.cn/xxgk/sqjs/gzsq/201 611/t20161122_23407318.html

Hai, Y. (2021). Poverty alleviation by education is a kind of awakening and discovery: in memory of the "Poverty Alleviation War" of a retired middle school principal in eastern China. Science Insights Education Frontiers, 8(2):1097-1107. DOI:

https://doi.org/10.15354/sief.21.rp001

Hanushek, E.A. (2011). The economic value of higher teacher quality. Economics of Education Review, 30(3):466-479. DOI:

https://doi.org/10.1016/j.econedurev.2010.12 .006

He, K. (2006). A correct understanding of the purpose, significance and connotation of "Educational Technology Ability Training for Primary and Secondary School Teachers." China Educational Technology, 13(11):20-

21. [Chinese]

https://www.cnki.com.cn/Article/CJFDTotal -ZDJY200611003.htm
He, X., \& Liu, Y. (2016, May 26) Realizing the dream of fairness with the help of "Education Cloud"-Qianxinan Autonomous Prefecture boldly explores applying the "Internet + education" model. Western Development News. Retrieved March 25, 2021 from http://xbkfb.gog.cn/system/2016/05/26/0149 33126.shtml?from=timeline\&isappinstalled $=$ $\underline{0}$

Jin, F. (2019, December 13). Qianxinan Prefecture: Singing the "141" Song of educational poverty alleviation. Retrieved April 3, 2021, from http://qxn.gog.cn/system/2019/12/13 /017459921.shtml

Li, H., Shen, L., \& Qian, D. (2017). Investigation and analysis of the current situation of education informatization in weak areas of China. e-Education Research, 38(8):50-

54+77. [Chinese] DOI: https://doi.org/10.13811/j.cnki.eer.2017.08.0 $\underline{08}$

Liu, Y. (2019). Southwest Guizhou: Good education in Jinzhou, Lizhou Benefiting People's Livelihood. Guizhou Today, 21(43):7677. [Chinese] http://www.cnki.com.cn/Article/CJFDTotalGZDD201943041.htm

Lu, S. (2017, March 23). Create a national model Wuhan No. 11 Middle School to send a live broadcast to Qianxi Southwest, and accurate assistance starts. Retrieved April 2, 2021, from:

http://www.ldqxn.com/news/zzxw/20170323 1372870.html

Qianxinan Education Public Service Platform. (2015, December, 28) The dream of smart education-the development of education informatization in Qianxinan Prefecture. Retrieved March 20, 2021, from http://yun.jzjyyun.cn/index.php?r=portal/con tent $/ \mathrm{view} \&$ sid $=522300 \& \mathrm{id}=358147 \&$ lid $=\& \mathrm{c}$ ontentid $=\&$ tp $=$

Science and Technology Department of the Ministry of Education of China. (2021, February 01). December 2020 Education Informatization and Cyber Security Monthly Report. Retrieved April 12, 2021, from 
Huang. Information Technology to Improve the Quality of Education in Guizhou, China.

https://www.ict.edu.cn/news/yuebao/n20210

201_76905.shtml

Southwestern Guizhou Prefecture Education Bureau. (2019). September 08). Education with the word "established" and the word "practical" benefit the people's livelihoodOur prefecture fully promotes the strategy of establishing the state of education and builds the foundation for a century. Qianxinan Daily, p.A2. Retrieved April 15, 2021, from http://www.qxnrb.com/epaper/qxnrb/html/20 19-09/08/content_75586.htm

Sun, Y. (2019, September 27). 70 Years of Magnificence, Building a New Era of Dreams: Like to see the new changes in the development of education in Southwest Guizhou. Colorful Guizhou Net. Retrieved March 10, 2021 from http://www.ddepc.cn/jiaoyu/201909/t201909 27_622095.shtml

Wang, H. (2021). Construction and perspective thinking of the training model of teachers' application ability in online class: Take $\mathrm{Si}-$ chuan cloud education as an example. Science Insights Education Frontiers, 8(1):975988. DOI:

https://doi.org/10.15354/sief.21.or007

Wei, F. (2017). Let "Education Cloud" Become a New "Engine" to promote the development of education: An investigation report on education informatization in Qianxinan Buyi and Miao autonomous prefecture of Guizhou.
Ethnic Education of China, 24(Z1):57-59.

DOI:

https://doi.org/10.16855/i.cnki.zgmziy.2017. z1.023

Xu, H., \& Luo, J. (2009). Research on the Application of Information Technology in the Development of Ethnic Culture Courses. Ethnic Education Research, 20(5):124-128. [Chinese] DOI: https://doi.org/10.15946/j.cnki.10017178.2009.05.008

Yang, X., \& Liang, L. (2006). Analyze the "three modes" of modern distance education in rural primary and secondary schools. $e$ Education Research, 26(1): 45-49. [Chinese] http://jpkc.scnu.edu.cn/xxjsjy/webcourse/ST UDY/NYGC/1004.PDF

Zha, B. (2019a, December 11). Because of the "E" and the "E," the education informatization of Qianxinan Prefecture sings the song of "cloud." Qianxinan Daily, p.A1. Retrieved April 15, 2021, from http:// www.qxnrb.com/epaper/qxnrb/html/201912/11/content_93585.htm

Zha, B. (2019b, December 15). This live broadcast crosses the mountains and seas, Ningbo Jiangbei and Cheng teachers in southwestern Guizhou Province to connect and teach and research simultaneously. Qianxinan Daily, p.A2. Retrieved April 10, 2021, from http://www.qxnrb.com/epaper/qxnrb/html/20 19-12/15/content 93734.htm 